\title{
Commentary \\ Aromatase inhibitors as adjuvant therapy for postmenopausal women: a therapeutic advance but many unresolved questions
}

Jennifer A Ligibel and Eric P Winer

Harvard Medical School, Dana-Farber Cancer Institute and Brigham and Women's Hospital, Boston, Massachusetts, USA

Corresponding author: Eric P Winer, ewiner@partners.org

Published: 11 November 2005

This article is online at $\mathrm{http}: / /$ breast-cancer-research.com/content/7/6/255

(c) 2005 BioMed Central Ltd
Breast Cancer Research 2005, 7:255-257 (DOI 10.1186/bcr1347)

trial compared the use of letrozole with placebo after 5 years of tamoxifen [7].

The primary end-point of these trials was disease-free or event-free survival, although the precise definition of this endpoint varied somewhat across trials. Regardless of the exact definition, each trial demonstrated a decrease in breast cancer events in women who had received an aromatase inhibitor. At a median of 68 months of follow up, the ATAC trial demonstrated a hazard ratio $(\mathrm{HR})$ of $0.83(95 \%$ confidence interval [Cl] 0.73-0.94) for women with hormone receptor positive breast cancer treated with anastrozole [2]. The absolute difference in events between anastrozole and tamoxifen was 3.3\% at 6 years. No survival difference has yet been demonstrated. The BIG 1-98 trial also demonstrated a significantly lower rate of breast cancer events in the aromatase inhibitor arm [4]. With a median follow up of 25.8 months, the HR for a breast cancer recurrence, second breast or nonbreast malignancy, or death from any cause was 0.81 (95\% Cl 0.70-0.93) in the letrozole arm as compared with the tamoxifen arm. Not surprisingly, given the short follow up of the trial, there was no difference in overall survival. Of note, there was a nonsignificant increase in nonbreast cancer related deaths in the letrozole arm, with an excess of cardiac and cerebrovascular deaths in this group $(P=0.08)$.

The crossover trials also demonstrated significantly lower rates of breast cancer events in patients treated with an aromatase inhibitor. The patient populations in these trials were somewhat different from those in ATAC and BIG 1-98, because patients were free of disease after 2-3 years of tamoxifen. In IES the HR for a recurrence of breast cancer, a contralateral cancer, or death from any cause at 30.6 months was 0.68 (95\% Cl 0.56-0.82) in the exemestane arm, which corresponded to a $4.7 \%$ absolute difference in event rates between the two groups [6]. The exemestane group also had a significantly lower risk for distant relapse (HR 0.66, 95\% Cl 
0.52-0.83) and for contralateral breast primary. In the ABCSG/ARNO trial, the HR for a locoregional recurrence, a distant recurrence, or a contralateral breast cancer at 3 years was $0.60(95 \% \mathrm{Cl} 0.44-0.81)$ in the crossover group compared with the group treated with 5 years of tamoxifen [5]. Again, there was a significantly lower risk for distant relapse in the anastrozole group $(\mathrm{HR} \quad 0.61,95 \% \mathrm{Cl}$ $0.42-0.87$ ) but no significant difference in overall survival at the time of this initial analysis.

The MA-17 trial looked the role of extended adjuvant endocrine therapy [7]. Women who completed 5 years of tamoxifen were randomly assigned to 5 years of letrozole or to placebo. The trial was stopped at the time of the first interim analysis, with a median follow up of 2.4 years. The letrozole arm demonstrated a significantly better disease-free survival, with a HR of 0.57 (95\% Cl 0.43-0.75). The actuarial 4 year disease-free survival was $93 \%$ for the letrozole arm and $87 \%$ for the placebo arm $(P<0.001)$. An update presented at the 2004 American Society of Clinical Oncology meeting [8] reported a marginally significant $(P=0.04)$ survival advantage for lymph node positive patients treated with letrozole. This trial, along with the crossover trials described above, demonstrated that sequential therapy with tamoxifen followed by an aromatase inhibitor is clearly more effective in preventing breast cancer events than tamoxifen alone.

In addition to examining the efficacy of the drugs, the adjuvant trials have also examined the tolerability and toxicity of the aromatase inhibitors $[9,10]$. In general, the drugs were well tolerated, with low rates of discontinuation due to adverse events. Many side effects, such as hot flashes, mood changes and weight gain, were similar in patients treated with aromatase inhibitors and tamoxifen. Patients treated with the aromatase inhibitors developed significantly more osteoporosis and fractures than did those treated with tamoxifen, but they did not appear to have the increased risk for clotting and endometrial pathology that has been seen with tamoxifen. The BIG 1-98 trial did demonstrate an excess of cardiac disease and deaths in patients treated with letrozole [4], and the ATAC study demonstrated an excess of approximately 20 nonbreast cancer related deaths in the anastrozole arm [3]. Although these differences did not reach statistical significance, further evaluation of the impact of aromatase inhibitors on women's overall health is needed. Unfortunately, the early stopping of several of the aromatase inhibitor trials based on the efficacy of the drugs may make it difficult to fully evaluate their toxicity.

There is consensus that the optimal adjuvant hormonal therapy for postmenopausal women with hormone receptor positive breast cancer should include an aromatase inhibitor in most settings [11]. However, the 'best' use of an aromatase inhibitor remains unclear. It is not known at this time whether women are best served by starting an a number of years followed by an aromatase inhibitor. Further data from the crossover arms of the BIG 1-98 trial may provide an answer to this question, but it will be several years before these data are mature. In the interim, three groups have designed models to evaluate the relative benefits of different treatment strategies [12,13]. A Markov model from our institution suggests that a crossover from tamoxifen to an aromatase inhibitor after 2-3 years may be the preferred strategy for the typical patient, in order to minimize the chance of recurrence over a 10- to 15-year time span [12]. Although such models can be helpful in analyzing complex data from a number of sources, they do not substitute for randomized clinical trials and are highly dependent on a range of assumptions. However, the models do emphasize the importance of ongoing crossover trials such as BIG 1-98. In the absence of an early survival benefit, it will be critical to allow these trials to proceed and the planned crossover data to mature so that it will be possible to determine whether initial aromatase inhibitor therapy or a crossover approach offers the best protection against subsequent breast cancer events.

A single approach may not be optimal for all patients. Based on characteristics of the tumor and patient, it is likely that different women will benefit from differing hormonal therapy strategies. Subset analyses of the ATAC and ABCGS/ARNO trials have suggested that the use of an aromatase inhibitor may be especially beneficial in women with estrogen receptor-positive and progesterone receptor-negative tumors $[5,14]$, and preoperative studies have demonstrated that aromatase inhibitors may also be more effective in women whose tumors are estrogen-receptor positive and overexpress the HER2 protein [15]. Gene microarray profiling has suggested that there may be signatures associated with resistance to tamoxifen [16], and it is possible that the aromatase inhibitors may be more effective in this setting as well. Hormone receptor positive breast cancer is comprised of at least three distinct tumor types as defined by clinical characteristics, single gene markers, and microarray analyses [17]: luminal A (typically estrogen receptor-positive, progesterone receptor-positive, and low grade); luminal $B$ (typically higher grade); and HER2-positive with coexpression of steroid hormone receptors. Each of these tumor types may require a somewhat different approach. Finally, as we gain a better understanding of the toxicity profile of the aromatase inhibitors, we may be able to predict which women are at greatest risk for side effects and who might therefore be considered better candidates for a shorter course of an aromatase inhibitor after tamoxifen or, in some situations, tamoxifen alone.

The aromatase inhibitors represent a major advance in adjuvant hormonal therapy for postmenopausal women with breast cancer. The current standard of care for a postmenopausal woman with early stage breast cancer would clearly include the use of an aromatase inhibitor, either upfront or after some period of tamoxifen use. Given the 
available data, it is difficult to conclude that one approach is superior to another. It is also important to remember that upfront use of an aromatase inhibitor probably precludes the use of other aromatase inhibitors after 5 years of therapy, an approach that demonstrated significant benefit in the MA-17 trial.

There are currently many unanswered questions regarding the optimal hormonal therapy regimen for postmenopausal women with early stage breast cancer. Recently completed and ongoing studies will address many of these issues, and it is important to withhold final judgment regarding the use of the aromatase inhibitors and tamoxifen until these data are available. The aromatase inhibitors clearly represent an advance in hormonal therapy for postmenopausal women. Over the next few years, several trials will help to guide their optimal use to guarantee that women in the years ahead will gain an ever-increasing benefit from adjuvant hormonal therapy.

\section{Competing interests}

EW has served on advisory boards for AstraZeneca, Pfizer and Novartis.

\section{References}

1. Group EBTC: Tamoxifen for early breast cancer: an overview of the randomized trials. Lancet 1998, 351:1451-1467.

2. Group AT: Results of the ATAC (Arimidex, Tamoxifen, Alone or in Combination) trial after completion of 5 years' adjuvant treatment for breast cancer. Lancet 2005, 365:60-62.

3. Group AT: Anastrozole alone or in combination with tamoxifen versus tamoxifen alone for adjuvant treatment of postmenopausal women with early breast cancer: first results of the ATC randomized trial. Lancet 2002, 359:2131-2139.

4. Thurlimann BJ, Keshaviah A, Mouridsen H, Mauriac L, Forbes JF, Paridaens R, Castiglione-Gertsch M, Gelber RD, Smith I, Goldhirsch A: BIG 1-98: Randomized double-blind phase III study to evaluate letrozole $(\mathrm{L})$ vs. tamoxifen $(T)$ as adjuvant endocrine therapy for postmenopausal women with receptorpositive breast cancer. J Clin Oncol 2005, 23(16S):511.

5. Jakesz R, Jonat W, Gnant M, Mittlboeck M, Greil R, Tausch C, Hilfrich J, Kwasny W, Menzel C, Samonigg $H$, et al:: Benefits of switching postmenopausal women with hormone-sensitive early breast cancer to anastrozole after 2 years adjuvant tamoxifen: combined results from 3,123 women enrolled in the ABCSG Trial 8 and the ARNO 95 Trial. Lancet 2005, 366:455-462.

6. Coombes RC, Hall E, Gibson LJ, Paridaens R, Jassem J, Delozier T, Jones SE, Alvarez I, Bertelli G, Ortmann O, et al.: A randomized trial of exemestane after two to three years of tamoxifen therapy in postmenopausal women with primary breast cancer. N Engl J Med 2004, 350:1081-1092.

7. Goss PE, Ingle JN, Martino S, Robert NJ, Muss HB, Piccart MJ, Castiglione M, Tu D, Shepherd LE, Pritchard Kl, et al:: A randomized trial of letrozole in postmenopausal women after five years of tamoxifen therapy for early-stage breast cancer. $N$ Engl J Med 2003. 349:1793-1802.

8. Goss PE, Ingle JN, Martino S, Robert NJ, Muss HB, Piccart MJ, Castiglione MM, Tu D, Shepherd LE, Pater JL: Updated analysis of the NCIC CTG MA.17 randomized placebo controlled trial of letrozole after five years of tamoxifen in postmenopausal women with early stage breast cancer. J Clin Oncol 2004, 22(14S):847

9. Fallowfield L, Cella D, Cuzick J, Francis S, Locker G, Howell A: Assessing the quality of life (OOL) of postmenopausal women randomized into the ATAC ('Arimidex', Tamoxifen, Alone or in Combination) adjuvant breast cancer trial. J Clin Oncol 2004, 22:4261-4271.

10. Whelan T, Goss P, Ingle J, Pater J, Shepherd L, Palmer M, Tu D, Robert N, Martino S, Muss H: Assessment of quality of life in $\mathrm{MA}-17$, a randomized placebo-controlled trial of letrozole in postmenopausal women following five years of tamoxifen. $J$ Clin Oncol 2004, 22(14S):517.

11. Winer EP, Hudis C, Burstein HJ, Wolff AC, Pritchard KI, Ingle JN, Chlebowski RT, Gelber R, Edge SB, Gralow J, et al.: American Society of Clinical Oncology Technology Panel assessment on the use of aromatase inhibitors as adjuvant therapy for postmenopausal women with hormone-receptor positive breast cancer: status report 2004. J Clin Oncol 2005, 23:619629.

12. Punglia RS, Kuntz KM, Winer EP, Weeks JC, Burstein HJ: Optimizing adjuvant endocrine therapy in postmenopausal women with early-stage breast cancer: a decision analysis. $J$ Clin Oncol 2005, 23:5178-5187.

13. Cuzick J, Howell A: Optimal timing of the use of an aromatase inhibitor in the adjuvant treatment of postmenopausal hormone receptor-positive breast cancer. J Clin Oncol 2005, 23(16S):658.

14. Group AT: Analysis of time to recurrence in the ATAC (arimidex, tamoxifen, alone or in combination) trial according to estrogen receptor and progesterone receptor status [abstract]. Breast Cancer Res Treat 2003, 82(1S):4.

15. Ellis MJ, Coop A, Singh B, Mauriac L, Llombert-Cussac A, Janicke F, Miller WR, Evans DB, Dugan M, Brady C, et al.: Letrozole is more effective neoadjuvant endocrine therapy than tamoxifen for ErbB-1 and/or ErbB-2-positive, estrogen receptor-positive primary breast cancer: evidence from a phase III randomized trial. J Clin Oncol 2001, 19:3808-3816.

16. Loi S, Piccart M, Haibe-Kains B, Desmedt C, Harris AL, Bergh J, Tutt A, Miller LD, Liu ET, Sotiriou C: Prediction of early relapses on tamoxifen in early-stage breast cancer: a potential tool for adjuvant aromatase inhibitor tailoring. J Clin Oncol 2005, 23(16S):509.

17. Perou CM, Sorlie T, Eisen MB, van de Rijn M, Jeffrey SS, Rees CA, Pollack JR, Ross DT, Johnsen H, Akslen LA, et al:: Molecular portraits of human breast cancers. Nature 2000, 406:747-752. 